\title{
The Transition Online: A Mixed-Methods Study of the Impact of COVID-19 on Students with Disabilities in Higher Education
}

\author{
Laura E Mullins $^{1} \&$ Jennifer Mitchell ${ }^{1}$ \\ ${ }^{1}$ Brock University, Canada \\ Correspondence: Laura E Mullins, Brock University, Canada. \\ Brock Library Open Access Publishing Fund.
}

Received: July 30, 2021

Accepted: September 1, 2021

Online Published: September 6, 2021

doi:10.5430/ijhe.v11n2p13

URL: https://doi.org/10.5430/ijhe.v11n2p13

\begin{abstract}
Following the World Health Organization's announcement of the global pandemic because of the Coronavirus Disease 2019, most Canadian universities transitioned to offering their courses exclusively online. One group affected by this transition was students with disabilities. Previous research has shown that the university experience for students with disabilities differs from those of their non-disabled peers. However, their unique needs are often not taken into consideration. As a result, students can become marginalized and alienated from the online classroom. In partnership with Student Accessibility Services, this research revealed the impact of the transition to online learning because of the pandemic for university students with disabilities. Students registered with Student Accessibility Services completed a survey about the effects of online learning during a pandemic on the students' lives, education, and instructional and accommodation. It was clear from the results that online education during COVID-19 affected all aspects of the students' lives, particularly to their mental health. This research provided a much-needed opportunity for students with disabilities to share the factors influencing their educational experience and identified recommendations instructors should consider when developing online courses to increase accessibility and improve engagement.
\end{abstract}

Keywords: higher education, online, students with disabilities, COVID-19

\section{Introduction}

\subsection{Introduce the Problem}

Following the World Health Organization's announcement of the global pandemic because of the Coronavirus Disease 2019 (COVID-19; Public Health Ontario, 2020), most Canadian universities announced they would transition to offering courses exclusively online. Instructors quickly adapted their curriculum to the online format. Enhanced by the uncertainty and fear associated with the pandemic, this process was challenging for all involved. This transition significantly affected students with disabilities (SWD). Earlier research has shown that the university experience for SWD differs from those of their non-disabled peers (e.g., Mullins \& Preyde, 2013). They face added challenges that affect their education (e.g., Dryer, 2018; McNicholl, Casey, Desmond, \& Gallagher, 2021; Mullins \& Preyde, 2013; Wolpinsky, 2014), yet their unique needs are often not considered (Grabinger, 2010). Outcomes of the rapid transition for this population and how best to develop curriculum when students must study exclusively online because of the COVID-19 pandemic have yet to be appreciated.

In partnership with Student Accessibility Services within a Canadian university, this research revealed the impact of the transition to online learning because of the pandemic for SWD. We administered an online survey to all students registered with disability services to explore the effects of online learning during a pandemic on the students' lives, education, and instructional and accommodation needs. We expected that students' experiences were challenging during the pandemic. Further, although the instructors, disability services and university appreciated student concerns, several technological, informational, attitudinal, and systemic barriers impeded students' success. Identifying and addressing these barriers should help improve accessibility, engagement, and success in online education and during the pandemic.

\subsection{Importance of the Problem}

Although more SWD are enrolled in higher education than ever before (Grimes, 2020), they still represent only 5-7\% of the student population at universities in Canada (McCloy \& DeClou, 2013). Approximately 22\% of those with 
disabilities earn a university degree (compared to 36\% of those without a disability) (Statistics Canada, 2007), and they are more likely to drop out than those without disabilities (Denhart, 2008; Statistics Canada, 2007). SWD face barriers to learning which can affect their academic experience, success, and overall well-being. Dryer (2018) reviewed several barriers related to institutional processes (e.g., difficulties transitioning to higher education, access to information, disclosure process, and negotiating accommodations), the physical environment (e.g., navigating the campus and classroom), and attitudinal barriers (e.g., lack of awareness, negative attitudes from peers, academic, and support staff, and stigmatization). How barriers are experienced can differ based on the unique nature of the students' disabilities (identified as impairment-related effects by Thomas [1999]) (Jacklin, 2011).

To help these students succeed, SWD are entitled to accessible and appropriate accommodations to address barriers to their education (Ontario Human Rights, n.d.). Most institutions have developed centers to facilitate supports and accommodation. Some accommodations include individual accommodations for courses (e.g., extensions on assignment, exam supports, \& note takers) and assistive technology (McNicholl et al., 2021). In addition, services are available to support students, such as transitional, case management, learning, and crisis supports. Universities often provide these services through Student Accessibility Services (SAS), which must comply with Ontario Human Rights Commission guidelines and the Accessibility for Ontarians with Disabilities Act (AODA, 2005). For each course, however, negotiating accommodations is often under the discretion of the course instructor. Instructors participate in the accommodation process, gaining knowledge about disability issues and ensuring student confidentiality (AODA, 2005). Although supported by university staff and services, this process means SWD can have a vastly unique experience depending on their instructors, departments, and faculties (Dryer, 2018).

Despite some negative perceptions identified in previous research, recent research has shown that faculty members desire to learn more about the needs of SWD and how best to support them (Westine et al., 2019). Pollock (2009) reported that instructors will provide accommodations, but they were cautious about any changes that jeopardized course integrity. The faculty also seemed to put the onus on the students and suggest that students need to be proactive when requesting accommodations (Pollock, 2009). A critical factor impeding this process is instructors' differing attitudes and willingness to implement accommodation, which adversely affects students' experience and success (Mullins \& Preyde, 2013; Quinlan, Bates, \& Angell, 2012; Sachs \& Schreuer, 2011).

These attitudes may stem from a medicalized orientation to disability. While they use this orientation for diagnosis, eligibility for services and accommodations within education, disability studies scholar Wendell (2006) critiqued the medicalization of disability. Wendell argued that "neither impairment nor disability can be defined purely in biomedical terms because social arrangements and expectations make essential contributions to impairment and disability, and to their absence" (p. 35). Wendell outlined a framework to describe five ways disability can be socially constructed:

(a) social conditions that cause or fail to prevent damage to people's bodies; (b) expectations of performance; (c) the physical and social organization of societies on the basis of a young, non-disabled, 'ideally shaped', the healthy adult male paradigm of citizens; (d) the failure or unwillingness to create ability among citizens who do not fit the paradigm; and (e) cultural representations, failures of representation, and expectations. (p. 45)

All these social forces are pervasive within the education systems and they are influenced by the cognitive and social authority of medicine. The consequences of this authority result in internalization of the medicalization of disability - also known as the hegemony of normalcy (Davis, 2013) - while other perspectives of disability are dismissed and degraded (Goldie, 2011). Further, within academics, instructors are awarded social authority based on their cognitive authority, placing them in positions of power.

Consequences of cognitive and social authority for SWD can include social abandonment, epistemic invalidation, failures of communication, gaps in knowledge, and alienation (Wendell, 2006) that can dictate the rest of their academic experience. A person can feel abandoned when their disability is undiagnosed or perceived to be fabricated. These forces can also lead to epistemic invalidation, which causes the person to question their own experiences. There can be communication failures and gaps in knowledge resulting from the modes of communication and expectations. For example, the relationship between the course instructor and the SWD can affect the course outcome. Unfortunately, the student can feel alienated, which is the isolation associated when their experiences are determined to be irrelevant or ignored. Alienation for SWD leads to the narrative that "all is well with us" (Cameron, 2013, p. 11) and the eagerness to conform and be accepted amongst their non-disabled peers. This narrative can affect students' willingness to disclose, further deteriorating their experiences. 
Fortunately, Universal Design for Learning (UDL) has been endorsed to improve SWD learning (Meyer, Rose, \& Gordon, 2014). UDL provides guidelines for instructors based on three learning principles: providing multiple a) forms of representation, b) means of action and expression, and c) means of engagement. These strategies reduce barriers to learning by producing flexible learning environments, which is beneficial for all students, regardless of ability (Meyer et al., 2014). Since the substantial advancements in technology, there is a need to explore students' experiences in online education and how UDL can improve these experiences (Dryer, 2018).

\subsection{Relevant Literature}

\subsubsection{Online Education for SWD}

Many accommodations embedded in online learning are valuable for SWD. Such as greater flexibility and convenience, a greater variety of modes of instruction, and reduced pressure for active responses to live discussions (Wuensch, Aziz, Ozan, Kishore, \& Tabrizi, 2008). Further, some of the applications available through the digital platforms include various communication and social learning tools, multiple examples, scaffolding, and different forms of expression (Grabinger, 2010). However, the onus still rests with the student being motivated and using self-monitoring strategies to succeed (Dowell \& Small, 2011; Hong, Haefner, \& Slekar, 2011; Klassen, Krawchuk, Lynch, \& Rajani, 2008).

Previous research demonstrated that online instruction had increased access to higher education for SWD, and some prefer and excel in the online environment (Verdinelli \& Kutner, 2016). When instructors incorporate web-based accommodations, the online experience can be helpful for SWD. For example, the ability to adjust sound, playback lectures or videos, or adding closed captioning can reduce barriers for students with hearing issues (Ewing, 2006). Similarly, the ability post comments in forums or discussion boards can reduce barriers for students with processing difficulties (Harasim, 1989). Heiman and Shemesh (2012) reported that SWD spent more time engaging with online platforms than peers without disabilities. These students also reported an increased motivation to pursue multiple paths to learning to achieve their academic goals (Heiman \& Shemesh, 2012).

However, online education can also further complicate the needs of SWD (Dryer, 2018; Fichten, Asuncion, \& Scapin, 2014; Stewart, 2012). Roberts and colleagues (2011) found that students felt their disability negatively affected their ability to succeed in online education. Online instruction can introduce additional barriers to learning, especially if UDL principles and web-based accessibility options are not included in the course (Dryer, 2018). For example, students must learn how to navigate various online learning platforms, and they may run into technical issues that may not be addressed without in-person support. These factors can produce frustration and additional barriers to learning (Wolpinsky, 2014). Alternatively, Wolpinsky found that self-determination, organization, and family and peer support facilitated success in online courses for SWD. Thus, it is crucial to consider the current climate and available support within the home. We must consider this influence as we endure a global pandemic.

\subsubsection{The Experience of Online Education due to COVID-19 for SWD}

The pandemic further exacerbated the issues with education (among other aspects of life). Traditionally, instructors design their courses around the mode of delivery, tailoring learning environments on learning objectives and content, target audience, and access to students (Moore, Dickson-Deane, \& Galyen, 2011). The requirement to transition all in-person courses to an online format quickly was challenging for instructors and students alike. The different formats likely limited the transparent exchange of ideas and the social awareness and interactions among classmates and the instructor (Wuensch et al., 2008). The impact of format of change to students' satisfaction, experience, and success has only begun to be examined.

According to the recent literature exploring the sudden transition to online learning for university students during COVID-19, the pandemic led to rapid changes, uncertainty, and anxiety (Dianito, Espinosa, Duran, \& Tus, 2021; Moawad, 2020), which resulted in financial, physical, and mental health challenges and increased isolation (Dianito et al., 2021; Zhang et al., 2021). In addition, some students had to change living arrangements, as students were encouraged to leave student housing and return home if possible. These changes caused tremendous stress among the students and had detrimental effects on students' learning and psychological health (Copeland et al., 2020).

Some students benefited from the built-in accessible features of online learning. Having a flexible learning schedule and re-watching recorded lectures enhanced students' understanding of the material (Lapitan et al., 2021). Unfortunately, COVID-19 and the transition to online learning exposed shortcomings of the current higher education, particularly for SWD (Ali, 2020; Rashid \& Yadav, 2020). Zhang and colleagues (2021) found that SWD were more concerned about online education and experienced more COVID-19 related adversities than their peers without disabilities. Diantio and colleagues (2021) found that the switch to online learning was not accessible for SWD. Students' concerns pertained to reduced face-to-face interaction with academic staff and peers, leading to isolation, 
lack of engagement and reduced motivation, difficulties with technology, changes in modes of instruction and assessment (Adnan, 2020; Lapitan, Tiangco, Sumalinog, Sabarillo, \& Diaz, 2021; Martin, 2020; Moawad, 2020). Students also reported difficulty studying in their home environment (Moawad, 2020) and accessing assistive technology (Dianito et al., 2021). These COVID-19 related stressors have been associated with maladaptive coping mechanisms (e.g., denial, substance use, and self-blame) (Umucu \& Lee, 2020). Research is needed to explore the challenges and concerns among SWD and what support might be helpful to improve educational experiences and student well-being (Rashid \& Yadav, 2020). Failing to account for these needs and provide resources for SWD and faculty represent issues of inequality in our education systems (Meleo-Erwin, Kollia, Fera, Jahren, \& Basch, 2021).

\subsection{Research Questions and Research Design}

Regarding the student experiences, we examined a) what was the impact of COVID-19 on the students' lives and education; $b$ ) what aspects of online learning facilitated or impeded their educational experience (considering various modes of assessment \& modes of instruction); c) what were the students' accommodation needs for online education; and e) how were these accommodations disclosed and implemented. We explored if the students' year of study, program, and type of disability influenced the experiences of SWD. We also provided students with an opportunity to express their concerns and offer recommendations to promote access to improve the educational experiences of SWD.

A social justice research design over two phases (Creswell, 2015) was used to understand the broad impact of COVID-19 and the transition to online learning for SWD at various levels of their education. In phase one, we conducted a convergent mixed-methods survey. Mixed-methods is a research method that involves collecting both qualitative and quantitative data (Creswell \& Poth, 2018). The convergent design allowed an integrated analysis that validated both sets of data (Creswell, 2015). In phase two, we further explored these experiences with students willing to be contacted for follow-up from a phenomenological perspective. This phase of the research is still underway and will be reported separately.

\section{Method}

\subsection{Study Site}

We conducted the research at a comprehensive university in Ontario, Canada. The university has eight faculties, including Applied Health Sciences, Education, Humanities, Mathematics \& Sciences, Social Sciences, Business, Fine \& Performing Arts and Graduate Studies. They support SWD through SAS, part of the Student Wellness and Accessibility Centre (which also provides Personal Counselling Services and Student Health Services). SAS provides support for approximately 1600-2200 students across all programs and levels of study. Students registered in the department have a variety of disabilities and accessibility needs (e.g., physical disabilities, sensory impairments, learning disabilities, and mental health disorders). The research was conducted in partnership with management from SAS and was reviewed by the institution's Research Ethics Board (\#20-035).

\subsection{Measures}

We developed the survey for this study to address several areas, including a) the impact of transitioning online on the students; b) forms of instructions and assessments; c) unique accommodation for online learning and how accommodations were disclosed; and d) feedback on SAS services. The survey began with general demographic information (e.g., age, identified gender, disabilities, and level and program of study). Next, we asked students enrolled in courses during the Winter 2020 semester to reflect on their experiences during that time, including any challenges they experienced and the impact the pandemic had on these experiences (open-ended questions). We asked students to rate the degree to which they felt their disability affected their ability to succeed in an online learning environment (5-point five-point Likert scale; 1 definitely not to definitely yes 5). Students were asked to rate various instructional and assessment methods that facilitated or impeded their education experience on a five-point Likert scale (-2 significantly impedes to +2 significantly facilitates). Students indicated if they were unsure and provided other methods of instruction and assessment.

We asked students to reflect on how they typically disclose their need for accommodations and whether this process differed from in-person courses. Students described if the process depended on something. Students were asked to report the type of accommodations requested for online courses (open-ended) and if accommodations differed from those required for in-person courses and rated the degree to which the accommodations were provided (5-point five-point Likert scale; 1 unsure to fully 5). Students also reported their satisfaction with the university's ability to accommodate their disability in online courses (5-point five-point Likert scale; 1 extremely dissatisfied to extremely satisfied 5). We adapted questions about the impact of online education and accommodations from the Students with Disabilities and Online Learning (SDOL) survey (Roberts et al., 2011). In the last section of the survey, students 
reported their concerns for the Fall of 2020 associated with online education due to COVID-19 restrictions (5-point five-point Likert scale; 1 not concerned at all to 5 extremely concerned).

\subsection{Procedures}

Management from SAS reviewed the survey and two graduate students (one with a disability) piloted it. Once completed, SAS distributed a survey to registered students between September 2020 via email using the Qualtrics Software System. Students were asked to contact the author if they needed alternative accommodations to complete the survey; however, none were requested. The survey took an average of 40 minutes to complete. The survey ended by asking about their willingness to be contacted for follow-up interviews and surveys to explore the lived experience of the transition online during the pandemic. We thanked participants and entered them into a draw for two $\$ 25$ Amazon gift e-cards.

\subsection{Analysis}

A mixed-methods joint analysis was conducted to analyze the survey data (Fetters, 2019). This process includes 1) separate analysis of quantitative and qualitative data, 2) development of a joint display of qualitative themes to related quantitative constructs, and 3) interpreting and describing results (Guetterman, Fetters, \& Creswell, 2015). Quantitative responses were entered into SPSS (IBM Corp, 2020) to conduct descriptive analysis. Although 302 students responded to the survey, 80 students ended after the demographic information (completed less than $22 \%$ of the survey) and were removed from the results. The demographic distribution was similar between those that completed and those that ended early (see appendix A). The data were further cleaned (missing and uncertain responses were coded as missing, and scales were recoded for consistency). Additional analyses were conducted to examine differences in types of disability, the program of study, and the process of disclosure (i.e., ANOVA \& chi-square analysis).

Qualitative responses were entered into MAXQDA 2020 (VERBI Software, 2019) to conduct an inductive content analysis (Elo \& Kyngäs, 2008). This process involved open coding, creating categories, and abstraction. We considered each response a meaning unit subject to multiple codes and categories. Categories were developed through consultation among the authors. In addition, we completed a word cloud (Bletzer, 2015) to provide a visual representation of all the terms about adverse impact on mental health, which was one of the most frequently referenced concern.

We merged data using joint displays (Creswell, 2015) linking qualitative categories to quantitative constructs. The joint display analysis provided an organizational structure to summarize findings, identified inconsistencies, and contextualized the two forms of data (Creswell, 2015). The results were reviewed with the authors' collaborators (i.e., SAS) and summarized into four areas: a) the impact of online education, b) assessment and instruction in online education, c) disclosure process for online courses, and d) accommodation for online education. Feedback for SAS was provided to those supports and not included in this report.

\section{Results}

\subsection{Participants}

Two hundred and twenty-two students completed most of the survey. Students ranged from 18 to 65 years old $(M=25$, $S D=8.8)$. Most of the students identified as female $(72 \%)$, a third as male $(23 \%)$, and two percent as other $(2 \%)$. Students were studying throughout all the university's faculties, with the majority from the Faculty of Social Sciences (33\%) and Faculty of Applied Health Sciences (24\%). The majority were undergraduate students (90\%), but some graduate $(29 \%)$ and diploma or other $(7 \%)$ students also responded. The most common disabilities reported were mental health (63\%), learning disabilities (36\%) and attention deficits hyperactivity disorder (ADHD; 31\%) (see figure 1). More than half of the students (52\%) reported more than one disability, with twenty percent reported both learning and mental health disabilities. 

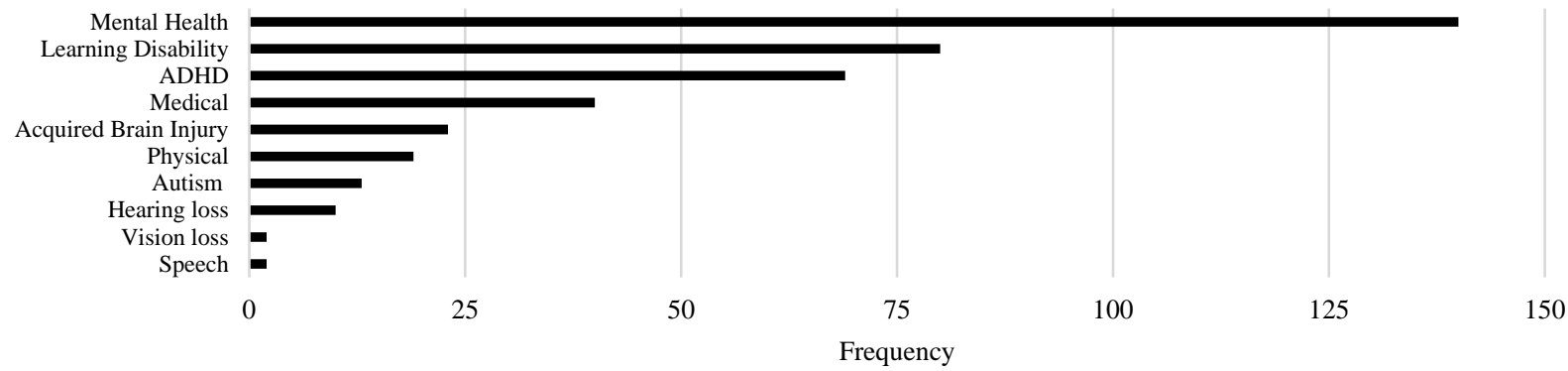

Figure 1. Student Reported Disabilities

\subsection{Impact of Online Education}

The transition to online education presented challenges to students' overall educational experiences and adversely affected their lives and mental health. A few students also identified some positive experiences.

\subsubsection{Challenges}

The students' challenges with the transition online to their education were organized into six areas: 1) online environment, 2) online education process, 3) ability to study from home, 4) instructor's facilitation of courses, 5) lack of access to supports and services, and 6) adverse outcomes of the transition online during the pandemic. Students rated their concerns about online education during the pandemic. Students were moderate to very concerned with all suggested areas $(M=3.1-3.9)$. A joint display was developed to illustrate the specific challenges related to their areas of concern (see appendix B).

The online environment itself was challenging because of the difficulty in learning and navigating various online platforms. Students experienced a variety of technical issues. They were moderately concerned about navigating online platforms $(M=3.2)$ and technical issues $(M=3.5)$.

Students reported many concerns about the online education process. They reported that the online environment was challenging because of the lack of face-to-face communication. As a result, many students felt disadvantaged by this form of education. Students were also struggling because there was an increased workload, and it was difficult to access information and keep track of the academic expectations. Students were moderately concerned about their access to information $(M=3.1)$. These issues created time management concerns, which was particularly challenging for those who already have trouble in this area. For example, a student wrote:

Online learning is not very ADHD-friendly. I have trouble switching from one task to another, especially without switching my environment. There are so many distractions at home and no physical reminders to properly manage our time. It also doesn't aid people that need to hear something to be able to learn it if professors are simply [posting] slides online. $\left(3^{\text {rd }}\right.$ year, undergraduate, Faculty of Humanities with ADHD, acquired brain injury, and mental health disability, P1006)

The online environment exacerbated impairment-related effects, particularly given that students are trying to study from home.

The ability to do schoolwork at home was a significant challenge for SWD. It was difficult for students to find a place to study effectively. There were many distractions at home (e.g., family \& housemates). Completing their education amongst these many distractions resulted in interpersonal challenges. Additionally, many students reported that it was challenging to focus on their studies for long periods on the computer and the lack of natural transitions throughout the day to provide structure. These challenges required additional time management skills to overcome. For example, one student wrote:

The ability to study and comprehend in a non-classroom environment was the main concern. I have taken online classes in the past, and they have never really worked for me. They require a high degree of self-organizational skills, which has always been challenging for me. I also struggle with asking for help or even remembering to email a professor for help so that I can get overwhelmed very quickly. Also, not being able to talk to instructors in person easily has been a huge barrier. Often, if I didn't understand or didn't know how to ask for help, talking directly to a professor or TA would make things more clear. $\left(3^{\text {rd }}\right.$ year, undergraduate, Faculty of Humanities with learning disability, P1292). 
How instructors facilitated their course was also a challenge for students, as students had difficulty communicating with their instructors, and there was a lack of explicit instructions and expectations. Students were also moderate to very concerned with communicating with faculty $(M=3.4)$ and access to information $(M=3.1)$. Differences in expectations between instructors were challenging for students. For example, one student wrote:

It can be very difficult between prof to prof. Each has a different way of presenting their lecture notes, assignments, quizzes, readings... So it can be very difficult figuring out how to meet the needs of each prof. Given yeah you experience this in person, but it's a different level of confusion when everything is handed out online. It's harder to really understand what they exactly want from us because it's basically us reading and now interpreting everything they say into our own thought. It's harder because some profs you can't put a face to a voice, and really disconnects you. ( $3^{\text {rd }}$ year, undergraduate, Faculty of Applied Health Science with acquired brain injury, P1263)

Students felt the responsibility to learn about each instructor's unique approaches and expectations made learning more difficult. Some participants also reported that some instructors were not prepared for the online courses. They reflected this concern in one of the student's comments:

It gives me a bunch of anxiety for no reason, and the way some professors are handling this is extremely awful. I appreciate live lectures, but I have no way to comprehend why a professor thinks it's reasonable to not post slides before the lecture. It doesn't help me prepare or focus in the lectures themself, so it feels as if I'm just wasting time by being present. $\left(2^{\text {nd }}\right.$ year undergraduate, Faculty of Mathematics and Sciences with ADHD, P1166)

Lack of preparedness may have been understandable during the initial transition to online education during the early stages of the pandemic but maybe less reasonable for their Fall 2020 courses. Further, failing to provide students with information before classes (e.g., by posting lecture slides) presented unnecessary barriers.

Students were also struggling with the lack of access to the university campus and related supports and services. Students reported challenges associated with the loss of their social connections, a place to study, or access to athletic activities, as expressed by a student who wrote:

I do well in lectures and seminars where I am given reminders by the prof and TA. It is also easier to connect with colleagues who can help with accountability. I am finding it very hard to get organized and begin tasks. I feel like I have no motivation nor any passion to want to learn. I LOVE going to campus and engaging with people, I hate online. ( $4^{\text {th }}$ year, Undergraduate, Faculty of Social Sciences with ADHD, P1172)

They were also concerned about their ability to communicate with SAS due to increased demand for services. Half the students believed they would require more supports from SAS given the transition to online education because of the impact of COVID-19.

Students reported on several adverse outcomes of the transition online during the pandemic. Many students reported general uncertainty about education and expectations. Students were concerned about a lack of motivation $(M=3.7)$ to complete the rest of the semester and about lower grades. They questioned their ability to succeed, worried about their future academics and ability to graduate. Some students questioned the quality of their education. A student wrote:

Fear and uncertainty definitely impacted my educational experience. As someone with anxiety, the threat of COVID-19 was often on my mind. My parents are both nurses as well, so you can imagine the amount of concern that was overwhelming me at the time. These stressors were a distraction, and they also lessened the quality of what I was able to complete. It was difficult because professors were scrambling, and no one knew the stress I was going through because they were obviously faced with other issues. $\left(2^{\text {nd }}\right.$ year undergraduate, Faculty of Social Sciences with mental health disability, P1076)

\subsubsection{Impact on Other Aspects of Their Lives}

Students reported many adverse effects on their lives associated with the transition online because of the impact of COVID-19. Many students had trouble with the lack of social integration, and isolation was among the greatest concerns $(M=3.7)$. Students emphasized the impact on their mental and physical health during this time. Students were stressed about the health of their family members given the uncertainness of the spread of the virus. They also identified financial issues and housing concerns. Several students lost employment due to COVID-19 and the restrictions, although some reported increased work hours. Students shared concerns about returning to their parent's home, and several continued to pay rent for student housing. Finally, students reported difficulty paying for their tuition. For example, one student wrote: 
The transition has been very challenging as I have a family and children also dealing with the stress and anxiety of the various aspects from COVID-19 and their own schooling. Online learning for me is very difficult as I learn best when I am face-to-face, and I have the ability to ask questions and learn from other students' interactions in the classroom as well. My mental health has already taken a beating with everything that is going on in the world, and this added impact has made my focus and willingness to start extremely challenging. $\left(2^{\text {nd }}\right.$ year, Undergraduate, Faculty of Applied Health Sciences with mental health disability, P1096 - emphasis added)

Although we did not directly ask students about their mental health, 577 comments reflected the adverse effects of transitioning online because of the pandemic had on aspects of their mental health. We developed a word cloud to visualize this impact (See figure 2). Students reported feelings of stress $(n=103)$, anxiety $(n=100)$, fear $(n=50)$, uncertainty $(n=47)$, lack of motivation $(n=45)$, worry $(n=38)$, isolation $(n=35)$ and depression $(n=28)$ among the most common mental health-related concerns. One student's comment illustrates many aspects of the impact on their mental health:

COVID-19 has taken away the hands-on aspect of learning that so many students, like myself, find essential in their learning. This, along with the lack of communication from staff at SAS at Brock, heightened my anxiety, stress levels, uncertainty, and feeling of worthlessness. This is because of the struggle online learning had posed on my mental health. ( $3^{\text {rd }}$ year, Undergraduate, Faculty of Applied Health Sciences with acquired brain injury, P1203 - emphasis added)

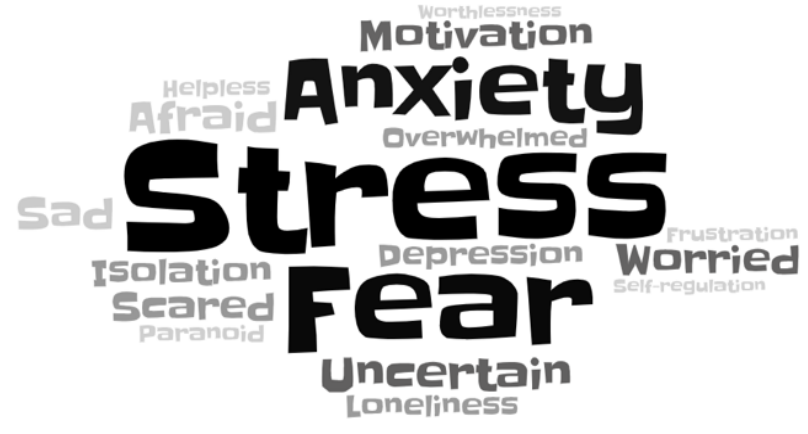

Figure 2. Impact of Online Education during COVID-19 on Mental Health

Note. The font size reflects the relative frequency of the concerns.

\subsubsection{Positive Experiences}

Fourteen students shared positive experiences of transitioning to online learning. A few students reported they preferred online education and could perform better-some positive aspects related to increased flexibility and convenience scheduling online learning. Further, the online environment was also more accessible to some students. More features embedded in online learning promote accessibility (such as closed captioning on pre-recording lectures and going back and watching pre-recorded lectures when needed). For example, a student with hearing loss wrote:

I think some of the challenges so far have been trying to get accustomed to the professor's lectures transitioning online rather in person. There are auto-closed captioning made available, and that has been helpful. I think it is actually a bit easier than being in an actual lecture setting because of the audio component has been easier (not being so distance or far away from the lecturer). (4 ${ }^{\text {th }}$ year, undergraduate, Faculty of Social Sciences with learning and mental health disabilities and hearing loss, P1133 - emphasis added)

The online environment also removed physical barriers to accessibility in the campus (i.e., finding accessible washrooms). A student with an acquired brain injury wrote:

The only positive thing I can take out of at-home learning is that there is a better chance I can manage my pain levels (due to disability) at home. Examples would be that I do not need to exhaust myself by walking around school looking for a comfortable seating that allows me to excel in/ focus on my schoolwork without distractions (while having a power outlet nearby, washrooms close enough, parking lot being close enough, and each class nearby). Pre-COVID this was extremely difficult at Brock as a student with disabilities. ( $3^{\text {rd }}$ year, undergraduate, Faculty of Applied Health Sciences, P1203 - emphasis added) 
Online education removed these physical barriers and allowed the student to focus on their academics.

\subsection{Assessment and Instruction in Online Education}

\subsubsection{Modes of Instruction}

Students rated different methods of instruction to indicate if they impeded (-2) or facilitated their learning (+2). Instructional methods that facilitated students' educational experience included watching recorded lectures, guided tutorials and video examples, short comprehension quizzes, class polls and coaching. Group learning activities were the only form of instruction that impeded the students' education experience (see figure 3). Challenges with group work included difficulties coordinating schedules, technical issues, and the risk of appearance of academic misconduct.

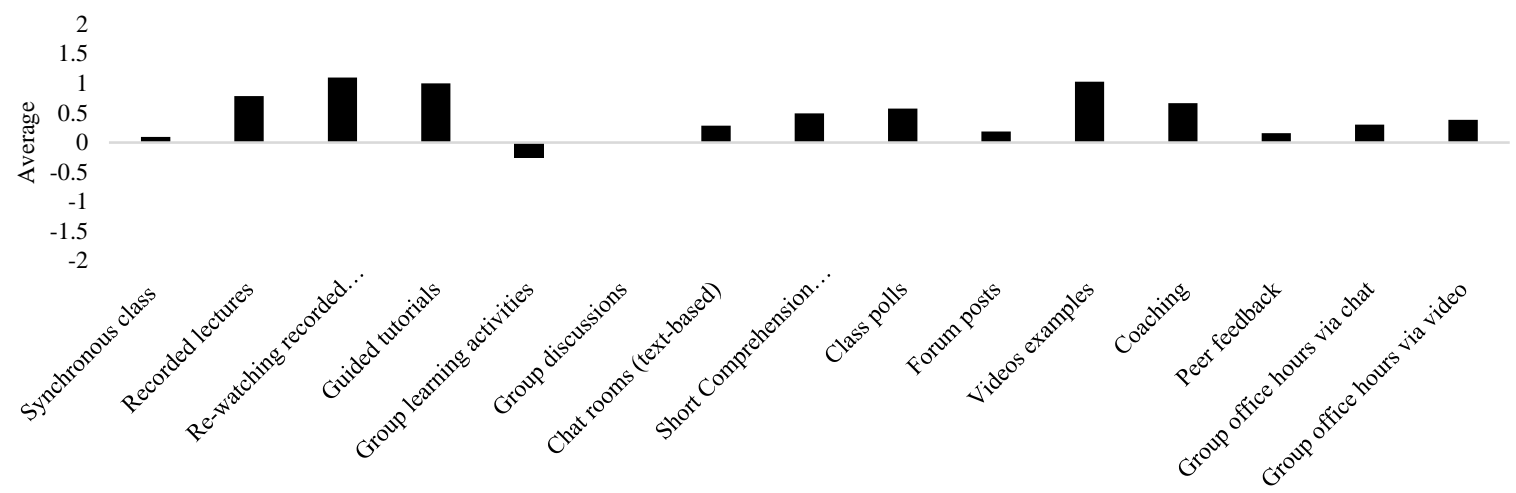

Figure 3. Forms of Online Instruction that Facilitate or Impede Learning

We conducted an ANOVA to further explore differences in forms of instruction based on types of disabilities. Although being able to review recorded lectures $(F(2,161)=3.63, p=0.029)$, guided tutorials $(F(2,147)=6.80, p=$ $0.001)$, and group office hours by chat $(F(2,146)=5.24, p=0.006)$ or video $(F(2,144)=3.39, p=0.036)$ were beneficial for all, these methods were significantly more helpful for students with comorbid disorders (see table 1).

Table 1. Forms of Instructions that Facilitated or Impeded Educational Experience

\begin{tabular}{lccc}
\hline & $\begin{array}{c}\text { Learning Disabilities } \\
\text { Forms of Online Instruction }\end{array}$ & $\begin{array}{c}\text { Mental Health } \\
(\mathrm{n}=36)\end{array}$ & $\begin{array}{c}\text { Both } \\
(\mathrm{n}=40)\end{array}$ \\
Synchronous class & 0.3 & 0.2 & 0.0 \\
Recorded lectures & $\mathbf{0 . 8}$ & $\mathbf{0 . 8}$ & $\mathbf{1 . 0}$ \\
Re-watching recorded lectures & $\mathbf{1 . 0}$ & $\mathbf{1 . 0}$ & $\mathbf{1 . 5}$ \\
Guided tutorials & $\mathbf{0 . 6}$ & $\mathbf{1 . 1}^{* *}$ & $\mathbf{1 . 3} * *$ \\
Group learning activities & 0.0 & $\mathbf{- 0 . 4}$ & $\mathbf{- 0 . 2}$ \\
Group discussions & 0.2 & $\mathbf{- 0 . 1}$ & 0.1 \\
Chat rooms (text-based) & 0.2 & 0.3 & 0.3 \\
Short Comprehension Quizzes & $\mathbf{0 . 5}$ & $\mathbf{0 . 6}$ & 0.2 \\
Class polls & $\mathbf{0 . 6}$ & $\mathbf{0 . 6}$ & $\mathbf{0 . 6}$ \\
Forum posts & 0.0 & 0.2 & 0.3 \\
Videos examples & $\mathbf{0 . 8}$ & $\mathbf{1 . 1}$ & $\mathbf{1 . 3}$ \\
Coaching & $\mathbf{0 . 6}$ & $\mathbf{0 . 6}$ & $\mathbf{0 . 9}$ \\
Peer feedback & 0.1 & 0.2 & $\mathbf{- 0 . 1}$ \\
Group office hours via chat & $0.1^{* *}$ & $0.2^{* *}$ & $\mathbf{0 . 8}$ \\
Group office hours via video & 0.4 & $0.2^{*}$ & $\mathbf{0 . 8}$ \\
\hline
\end{tabular}

$* \mathrm{p}>0.05$

$* * \mathrm{p}>0.001$ 


\subsubsection{Modes of Assessment}

Students also rated different assessment methods to indicate if they impeded (-2) or facilitated their education $(+2)$. Overall, students reported group work and presentations impeded their education. Students' responses to the forms of assessments were similar, regardless of whether they had learning or mental health disabilities (no significant differences). As a student with multiple disabilities wrote:

Executive functioning issues with starting the course and organizing it. I struggle following written instructions and miss being able to talk to the professors or hear verbal instructions. With online learning, I find that participation grades are written, which are a struggle for me. There are far more written assignments as well, I'm assuming replacing exams and writing is such a struggle for me. I do far better at exams but many courses are offering written exams. With writing difficulty I feel like I'm at a disadvantage. ( $3^{\text {rd }}$ year, Undergraduate student, Faculty of Social Sciences with learning, physical and mental health disabilities and ADHD, P1010).

Undergraduate students reported that tests and exams were better for them than graduate students (see figure 4). Graduate students were indifferent towards short answer quizzes but felt long answer quizzes or longer exams impeded their learning. Graduate students reported that written assignments facilitated their learning.

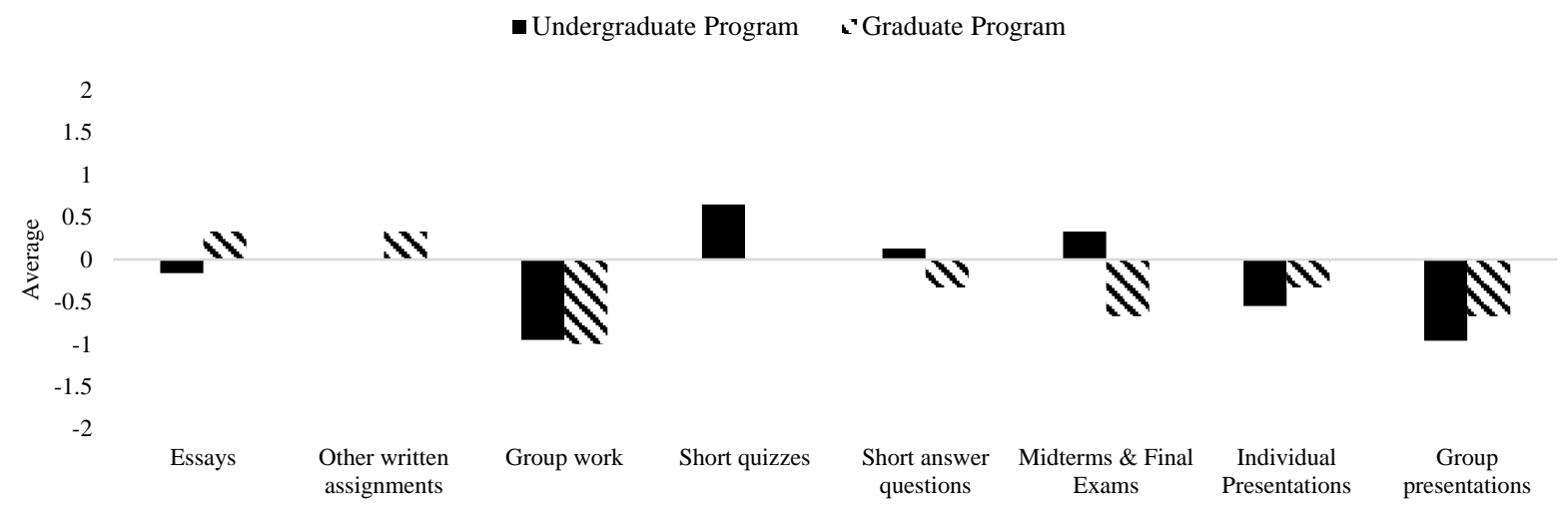

Figure 4. Forms of Online Assessment that Facilitate or Impede Learning

Note: Differences were not statistically significant.

\subsection{Disclosure Process for Online Courses}

Although most students (53\%) disclosed their need for accommodations through SAS and directly to their instructors, $21 \%$ only disclosed through SAS, and $14 \%$ reported that how they disclosed depended on the course and instructor. When asked if this process differed from in-person courses, $28 \%$ of students reported it was different, and $24 \%$ reported it depended on the course or instructor. This difference was significant $\left(\chi^{2}(15)=39.7, p>.001\right)$. Most of the students who reported a difference in their disclosure process indicated they would have typically disclosed personally to their instructor in addition to the SAS process.

Three common factors influenced the disclosure process for online learning. Students described the challenges associated with their inability to have an in-person discussion with instructors (e.g., during office hours or before or after classes). For example, an undergraduate student wrote about the challenges with disclosing online,

It is much, much harder to disclose online. If I don't have to, I don't, but that is not currently the case. It is awful emailing a prof you have never meant to ask for accommodations. At least in person, you can read body language during the response to gauge how you will have to communicate further. With email, there is no tone, and sometimes I can't tell if they are willing to work with me or frustrated with me. $\left(4^{\text {th }}\right.$ year undergraduate, School of Business with mental health and medical disabilities, P1050)

Without face-to-face discussions, students must disclose their accommodation needs through email. Students reported difficulty with email. For example, "there is no tone, and sometimes I can't tell if they are willing to work with me or frustrated with me" ( $4^{\text {th }}$ year Undergraduate, School of Business). Further, a student with mental health and learning disabilities wrote about how this process felt too formal:

It's a lot harder to talk about in an email. It makes it so formal and harder to word. I prefer to talk to instructors about accommodations in a more informal manner, like before or after class. I'm not ashamed or hide my 
diagnosis, it's something that makes some things more difficult, but in that, it shows strengths in other aspects. ( $4^{\text {th }}$ year, Undergraduate, School of Business with learning disability and mental health, P1221)

Further, the disclosure process was contingent on the comfort level and receptivity of the instructor.

\subsection{Accommodation for Online Education}

\subsubsection{Types of Accommodations}

Most students $(73 \%)$ requested accommodations for their online courses. The most common accommodations were for exams $(n=144)$ and extensions for assignments $(n=80)$. Thirty-two students requested note takers. The most common accommodation for exams was for extra time $(n=115)$. Additional accommodations were limitations on exam scheduling and the opportunity to have breaks, ask clarification questions, use a calculator, use editing software or assistive technology, have exams printed, use notes, and write in the SAS testing center. Additional course accommodations (requested by $<6$ students) included accommodations for lectures (shorter duration, recordings, audio examples, and notes), alternative expectations for assignments, and leniency in participation.

There were differences in the type of accommodation students required for online courses. Almost thirty percent (29\%) of students reported different accommodations for online courses, and 18\% reported that their accommodation needs would depend on the course. Extensions on assignments were the most common unique accommodation $(n=37)$. Students also required leniency in attendance and participation $(n=11)$. Students reported a need for some form of support with taking notes $(n=35)$, space to write exams $(n=20)$, additional time on exams $(n=16)$ and alternatives to group assignments $(n=5)$.

Twenty-seven percent of students required any additional specialized/adaptive technology (e.g., software, hardware) to work in an online environment. The most common adaptive technology requests were for text to speech programs $(n=$ $19)$, speech to text programs $(n=16)$, and closed captions $(n=6)$. A new computer was the most common adaptive hardware request $(n=4)$.

Five percent $(n=27)$ of students required fewer accommodations for online courses, whereas a few students referenced the need for additional accommodations. Some students $(14 \%)$ reported that they did not need any accommodations or had requested none yet.

\subsubsection{Implementation of Accommodations}

The students' reports on the degree to which accommodations were implemented are summarised in appendix C. Forty-seven students reported accommodations were mainly implemented, and 51 reported they were fully implemented. However, more students were unsure $(n=56)$. Students were somewhat satisfied with their accommodations $(n=71)$. Students identified several challenges associated with their accommodations, including lack of access to technology or technological issues and attitudinal barriers of some instructors. For example, a student wrote, "I had originally been given extensions on examinations for in-person courses. I had also requested oral exams or replacing the exam with a term paper of equal weight but was denied on the grounds that the university did not give 'handouts" ( $4^{\text {th }}$ year, undergraduate, Faculty of Social Sciences with learning and mental health disabilities and acquired brain injury, P1105). Some of these attitudes appeared to stem from a misunderstanding of the students' disabilities and need for accommodations. For example, another student wrote, "Video examples in lectures in person required closed captioning but the instructor often refuses and tells the students to "listen closer" ( $4^{\text {th }}$ year, undergraduate, Faculty of Mathematics and Science with learning and mental health disabilities, autism, and chronic pain, P1132). Several challenges were associated with systemic barriers, including unclear dissemination of information, the accommodation process, uncertainty about accommodations, and lack of access, as some accommodations could not be provided because of the online environment or COVID-19 related restrictions.

\section{Discussion}

\subsection{Summary of the Results}

Online education during COVID-19 negatively affected all aspects of the students' lives. The uncertainty associated with the pandemic and changes to their education particularly affected their mental health. The online environment presented many challenges for students, as they faced many technological issues (e.g., technical difficulties and navigating platforms). Students also had difficulty studying from home (e.g., lack of transitions, time management and distractions at home) and how the instructors initially facilitated courses. Students struggled with the loss of access to supports and services on campus. However, online education was not all negative. Some students reported positive experiences in the online environment, as it was free from physical barriers at the university, required fewer accommodations, and allowed for added supports (e.g., re-watching recorded lectures). Other modes of instruction 
that facilitated learning included guided tutorials and video examples, short comprehension quizzes, class polls, and coaching. Group learning activities and assignments impeded the overall educational experience. For assessment, undergraduate students reported that tests and exams were better indicators of performance, whereas graduate students preferred written assignments.

The most common accommodations for online education during the pandemics were additional time to complete assignments and exams. Over a quarter of the students required additional adaptive technology for their online courses. Unfortunately, students were more reluctant to personally disclose to their instructors than with traditional in-person learning to access accommodations. The students value face-to-face conversations about their learning needs, which is difficult to replicate via email. Also, the receptivity of their instructors influenced their likelihood of disclosing.

\subsection{Comparison of the Results with the Literature}

Several characteristics of in-person education are helpful, including naturalistic social and spatial awareness and connection, the physical arrangement of the classroom, ease of interaction with other students, clarity and efficiency of communication, direct and immediate feedback, and perceived reliability of assessments (Wuensch et al., 2008). However, this research demonstrated that the challenges with online learning during a pandemic outweighed these advantages. This study adds to the growing body of literature identifying these challenges (Adnan, 2020; Ali, 2020; Dianito et al., 2021; Lapitan et al., 2021; Martin, 2020; Meleo-Erwin et al., 2021; Moawad, 2020; Umucu \& Lee, 2020, 2020; Zhang et al., 2021).

The results provide continued evidence for the social creation and perpetuation of disability within the education system. All five of Wendell's (2006) forces representing the ways disability is socially constructed were evidenced, and many became worse through the process of students transitioning online during the pandemic. First, considering the "social conditions that cause or fail to prevent damage to people's bodies" (p. 45), students reported feeling isolated when asked to leave campus and return home. Students lost access to resources and social connections. Students expressed that their mental health and feelings of loneliness were severely affected during this time. The condition in which students were expected to learn was further disabling as students were forced to sit behind a computer screen for long periods, without the typical transitions throughout the day.

When the announcement was made that the rest of the Winter 2020 semester would be online, many instructors still expected students to complete the coursework for the semester by adjusting the tests and assignments to be completed in an online format. Thus, the "expectations of performance" (Wendell, 2006, p. 45) remained the same for students, despite the change in context. For some, the expectations increased as it appeared instructors felt students had more time to allocate to their academics. There was little recognition for the competing expectations at home, the social, physical, and mental impact of the pandemic over and above their limitations associated with their disability. Students reported reduced motivation to complete their tasks, given the uncertainties of the current state of the pandemic. Further, SWD were expected to perform the same academically, although accommodations were not fully implemented during the transition.

The university maintained an expectation of a paradigm citizen, which is a "young, non-disabled, 'ideally shaped', healthy adult male" (Wendell, 2006, p. 45), yet this did not represent the sampled students. Students were expected to transition online but provided few resources for navigating various types of student databases and videoconferencing platforms. It was also assumed that students would have access to technology and internet connection at home. Adjusting to an online learning environment was a barrier reported by students that led to additional anxieties. Further, some of the students lost access to child support (daycares and K-12 schools were deemed non-essential) and had to home school their children while balancing their coursework.

The "failure or unwillingness to create ability among citizens who do not fit the paradigm" (Wendell, 2006, p. 45) was clear, as some accommodations were not provided or not available. Failures of representation within our culture need to be acknowledged, as some students benefited from online learning with increased flexibility and accommodations. However, this accommodation was not available for all courses until society required it as a safety measure associated with the pandemic.

Relatedly, students appeared to struggle with the consequences of cognitive and social authority (Wendell, 2006). Due to the increased demand for SAS, students were expected to advocate for themselves and contact the SAS office to express the accommodations needed to succeed. Some students were reluctant to disclose their accommodations to instructors during the transition online as they did not want to be seen as an inconvenience or were concerned that their disability and accommodation needs would be rejected or underappreciated. Unfortunately, a few instructors denied accommodations on the basis that "universities do not give out handouts" (P1105), demonstrating epistemic 
invalidation. Students appeared to be concerned about being alienated due to their disability, resulting in a desire to conform to transitional expectations of academia.

\subsection{Evaluation}

The mixed-methods research design allowed students to rate their experiences and contextualize their experiences through open-ended questions. The survey allowed students to express their concerns and identify the barriers that hindered their academic achievement and well-being when transitioning to online learning during a pandemic. These methods allow for more accurate representations of the SWD experiences, provided students with an opportunity to describe their unique circumstances, and reduced the likelihood responses were limited by options available.

The study captured the student experience transitioning to online learning during the Winter 2020 semester, and impact of many areas of uncertainty SWD experienced during such unprecedented times. The study had a diverse representative sample of the student population (e.g., different academic disciplines and levels of study across the university). Additional survey items were developed specifically for this study, which were valuable from an academic and practical perspective. However, as we developed the survey for the project, it may not represent a reliable indication of student experiences. Roberts and colleagues (2011) and a similar study by another Canadian university informed the questions to address these issues. SWD and those that provide accessibility services at the university also reviewed the survey.

However, the generality of the results may be limited as all the students sampled were from one university. Additionally, since we released the survey in the Fall 2020 semester, it should be recognized that student's attitudes towards online learning may have shifted throughout the academic year. It also remains unclear how much of the experience of online learning was affected by the uncertainty of the early stages of the global pandemic or online education.

Another possible limitation is the potential for biases in the students' reports, and it may have unfairly represented the educational experience. This concern is similar to student evaluations of teaching, though it is a commonly used indicator of instructor performance in higher education (Esarey \& Valdes, 2020). Students were made aware that their responses would not affect their academic standing or supports through SAS.

\section{Recommendations \& Conclusions}

\subsection{Recommendations for Research}

Future research should continue to explore the lived experience of the transition online for SWD. It is critical to determine the impact of being a post-secondary student through such unprecedented times and the general fears and anxieties associated with the virus. Future research should explore the mental health concerns that students experienced during the pandemic and evaluate interventions designed to address and prevent these challenges. Research should identify academic accommodations that facilitate online learning and what additional services and supports are essential for SWD. Additionally, it would be valuable to augment the results with the perspective of instructors and SAS. Although we identified some differences, future research should consider how online learning affected different disciplines and levels of study, examine unique concerns associated with different forms of impairment-related effects, and explore issues of intersectionality within and among minority groups.

\subsection{Implications for Practice}

We developed ten recommendations instructors should consider when developing online courses. Instructors should:

1. recognize that students with disabilities are struggling but appreciate they are trying;

2. be aware that students are less likely to disclose their need for accommodation personally—still, they have the same, if not more, accommodation needs;

3. provide students with an opportunity to meet to discuss their accommodation needs early in the semester;

4. minimize the number of different platforms and programs;

5. reduce the number of more minor requirements for students;

6. outline all expectations and due dates (even for ungraded components) in the course outline;

7. reduce the number of written forms of instruction and consider adding video examples or developing guided tutorials;

8. record lectures (either in advance or during synchronous classes) and make the recordings available to students for future review; 
9. consider offing a variety of forms of assessment and reduce group assignments; and

10. be flexible - build flexibility with deadlines and extensions to due dates when setting up the course schedule and offer students extensions on assignments when requested.

These recommendations are consistent with the principles of UDL and include multiple forms of representation, expression, and engagement for students (Meyer et al., 2014). These strategies may reduce barriers to learning by promoting more accessible, flexible learning environments, reduce the need for accommodations, and should be beneficial for all students regardless of their abilities. Future research is needed to evaluate the degree to which these recommendations lead to improved educational outcomes.

\subsection{Conclusions}

Although online education can be advantageous for some SWD, particularly with built-in accessibility features, online education can also exacerbate existing challenges and present additional barriers to learning. It is vital to provide students options for how their courses are delivered, given their unique needs and preferences.

Although students need to develop self-advocacy skills, the process of disclosing accommodation needs can be challenging and discouraging, particularly for students with invisible disabilities (Bruce \& Aylward, 2021; Mullins \& Preyde, 2013; Pfeifer, Reiter, Cordero, \& Stanton, 2021) and for online courses (Barnard-Brak \& Sulak, 2010; Roberts et al., 2011). At the same time, instructors need to be more receptive to students and promote opportunities for students to discuss their accommodation. Institutions could also improve the process for securing accommodations. Feedback and engagement from faculty, students, and service providers could collectively identify opportunities for improvement.

This research provided a much-needed opportunity for SWD to share their educational experience during the pandemic. The research identified areas of challenge and concern and how support could be provided. Participants may have been empowered by sharing their experiences with their university and the larger community. Students may have also gained a greater understanding of their experience and may have felt less alienated. We hope this research will increase awareness and empathy for SWS, resulting in improved student/instructor relations, accommodations, and success. These voices should be valuable to instructors, supports and services, and the academic administration to appreciate the barriers SWD face. These results may be helpful to develop resources for instructors and provide further support in advocating for increased resources to address these systemic barriers.

\section{References}

Adnan, M. (2020). Online learning amid the COVID-19 pandemic: Students perspectives. Journal of Pedagogical Sociology and Psychology, 1(2), 45-51. https://doi.org/10.33902/JPSP.2020261309

Ali, W. (2020). Online and remote learning in higher education institutes: A necessity in light of COVID-19 pandemic. Higher Education Studies, 10(3), 16. https://doi.org/10.5539/hes.v10n3p16

Barnard-Brak, L., \& Sulak, T. (2010). Online versus face-to-face accommodations among college students with disabilities. American Journal of Distance Education, 24(2), 81-91. https://doi.org/10.1080/08923641003604251

Bletzer, K. V. (2015). Visualizing the qualitative: Making sense of written comments from an evaluative satisfaction survey. Journal of Educational Evaluation for Health Professions, 12. https://doi.org/10.3352/jeehp.2015.12.12

Bruce, C., \& Aylward, M. L. (2021). Disability and self-advocacy experiences in university learning contexts. Scandinavian Journal of Disability Research, 23(1), 14-26. (Disabled Students and University Faculty). https://doi.org/10.16993/sjdr.741

Cameron, C. (2013). Alienation. In C. Cameron, Disability Studies: A Student's Guide (pp. 11-13). SAGE. https://doi.org/10.4135/9781473957701.n4

Creswell, J. W. (2015). A concise introduction to mixed methods research. SAGE.

Creswell, J. W., \& Poth, C. N. (2018). Qualitative inquiry \& research design: Choosing among five approaches (Fourth edition). Los Angeles: SAGE.

Davis, L. J. (2013). Introduction: Normality, power, and culture. In L. J. Davis, The Disability Studies Reader (4th ed., pp. 1-18).

Denhart, H. (2008). Deconstructing barriers: Perceptions of students labeled with learning disabilities in higher education. Journal of Learning Disabilities, 41(6), 483-497. https://doi.org/10.1177/0022219408321151 
Dianito, A. J., Espinosa, J., Duran, J., \& Tus, J. (2021). A glimpse into the lived experiences and challenges faced of PWD students towards online learning in the Philippines amidst COVID-19 pandemic. International Journal Of Advance Research And Innovative Ideas In Education, 7, 2021. https://doi.org/10.6084/m9.figshare.14033435.v1

Dowell, D. J., \& Small, F. A. (2011). What is the impact of online resource materials on student self-learning strategies? Journal of Marketing Education, 33(2), 140-148. https://doi.org/10.1007/s40692-017-0083-8

Dryer, R. (2018). Equity issues for students with disabilities. In H. Marcus A, C. U. Krägeloh, R. Dryer, F. Moir, D. R. Billington, \& A. G. Hill (Eds.), Wellbeing in Higher Education: Cultivating a Healthy Lifestyle Among Faculty and Students (1st ed., pp. 174-186). Routledge. https://doi.org/10.4324/9781315641539-17

Elo, S., \& Kyngäs, H. (2008). The qualitative content analysis process. Journal of Advanced Nursing, 62(1), 107-115. https://doi.org/10.1111/j.1365-2648.2007.04569.x

Esarey, J., \& Valdes, N. (2020). Unbiased, reliable, and valid student evaluations can still be unfair. Assessment \& Evaluation in Higher Education, 45(8), 1106-1120. https://doi.org/10.1080/02602938.2020.1724875

Ewing, K. M. (2006). Graduate students' perceptions of online learning in a multiple disabilities education course (pp. 1-145). Gallaudet University.

Fetters, M. D. (2019). The mixed methods research workbook: Activities for designing, implementing, and publishing projects (Vol. 7). SAGE.

Fichten, C. S., Asuncion, J., \& Scapin, R. (2014). Digital technology, learning, and postsecondary students with disabilities: Where we've been and where we're going. Journal of Postsecondary Education and Disability, 27(4), 369-379. http://www.ahead.org/publications/jped

Goldie, J. G. (2011). The ethics of listening and responding to patients' narratives: Implications for practice. The British Journal of General Practice, 61(585), 306-307. https://doi.org/10.3399/bjgp11X568143

Government of Ontario. (2005). Accessibility for Ontarians with Disabilities Act, 2005.

Grabinger, S. (2010). A framework for supporting postsecondary learners with psychiatric disabilities in online environments. Electronic Journal of E-Learning, 8(2), 101-110. http://academic-conferences.org/ejournals.htm

Grimes, S. (2020). Student suggestions for improving learning at university for those with learning challenges/disability. In G. Crimmins (Ed.), Strategies for Supporting Inclusion and Diversity in the Academy: Higher Education, Aspiration and Inequality (pp. 329-352). Cham: Springer International Publishing. https://doi.org/10.1007/978-3-030-43593-6_17

Guetterman, T. C., Fetters, M. D., \& Creswell, J. W. (2015). Integrating quantitative and qualitative results in health science mixed methods research through joint displays. Annals of Family Medicine, 13(6), 554-561. https://doi.org/10.1370/afm.1865

Harasim, L. M. (1989). Online education: An environment for collaboration and intellectual amplification. Educational Evaluation Centre, Ontario Institute for Studies in Education.

Heiman, T., \& Shemesh, D. O. (2012). Students with LD in higher education: Use and contribution of assistive technology and website courses and their correlation to students' hope and well-being. Journal of Learning Disabilities, 45(4), 308-318. https://doi.org/10.1177/0022219410392047

Hong, B., Haefner, L., \& Slekar, T. (2011). Faculty attitudes and knowledge toward promoting self-determination and self-directed learning for college students with and without disabilities. International Journal of Teaching and Learning in Higher Education, 23(2), 175-185. http://www.isetl.org/ijtlhe

IBM Corp. (2020). IBM SPSS Statistics for MAC (Version Version 27.0). Armonk, NY: IBM Corp.

Jacklin, A. (2011). To be or not to be 'a disabled student' in higher education: The case of a postgraduate 'non-declaring' (disabled) student. Journal of Research in Special Educational Needs, 11(2), 99-106. https://doi.org/10.1111/j.1471-3802.2010.01157.x

Klassen, R. M., Krawchuk, L. L., Lynch, S. L., \& Rajani, S. (2008). Procrastination and motivation of undergraduates with learning disabilities: A Mixed-Methods inquiry. Learning Disabilities Research \& Practice, 23(3), 137-147. https://doi.org/10.1111/j.1540-5826.2008.00271.x

Lapitan, L. D. S., Tiangco, C. E., Sumalinog, D. A. G., Sabarillo, N. S., \& Diaz, J. M. (2021). An effective blended online teaching and learning strategy during the COVID-19 pandemic. Education for Chemical Engineers, 35, 116-131. https://doi.org/10.1016/j.ece.2021.01.012 
Long, R. E., \& Stabler, A. (2021). "This is NOT okay:" Building a creative collective against academic ableism. Journal of Curriculum and Pedagogy, 1-27. https://doi.org/10.1080/15505170.2021.1926374

Martin, L. (2020). Foundations for good practice: The student experience of online learning in Australian higher education during the COVID-19 pandemic. In Australian Government Tertiary Education Quality and Standards Agency. Australian Government Tertiary Education Quality and Standards Agency. Retrieved from https://eric.ed.gov/?id=ED610395

McCloy, U., \& DeClou, L. (2013). Disability in Ontario: Postsecondary education participation rates, student experience and labour market outcomes. Toronto: Higher Education Quality Council of Ontario. Retrieved from Higher Education Quality Council of Ontario website: http://hdl.voced.edu.au/10707/333402

McNicholl, A., Casey, H., Desmond, D., \& Gallagher, P. (2021). The impact of assistive technology use for students with disabilities in higher education: A systematic review. Disability and Rehabilitation: Assistive Technology, 16(2), 130-143. https://doi.org/10.1080/17483107.2019.1642395

Meleo-Erwin, Z., Kollia, B., Fera, J., Jahren, A., \& Basch, C. (2021). Online support information for students with disabilities in colleges and universities during the COVID-19 pandemic. Disability and Health Journal, 14(1), 101013. https://doi.org/10.1016/j.dhjo.2020.101013

Meyer, A., Rose, D. H., \& Gordon, D. (2014). Universal Design for Learning: Theory and Practice. CAST, Incorporated.

Moawad, R. A. (2020). Online learning during the COVID-19 pandemic and academic stress in university students. Romanian Journal for Multidimensional Education / Revista Romaneasca Pentru Educatie Multidimensionala, 12, 100-107. https://doi.org/10.18662/rrem/12.1sup2/252

Moore, J. L., Dickson-Deane, C., \& Galyen, K. (2011). E-learning, online learning, and distance learning environments: Are they the same? The Internet and Higher Education, 14(2), 129-135. https://doi.org/10.1016/j.iheduc.2010.10.001

Mullins, L., \& Preyde, M. (2013). The lived experience of students with an invisible disability at a Canadian university. Disability \& Society, 28(2), 147-160. https://doi.org/10.1080/09687599.2012.752127

Ontario Human Rights, C. (n.d.). Accommodating students with disabilities-Roles and responsibilities (fact sheet). Ontario Human Rights Commission. Retrieved from http://www.ohrc.on.ca/en/accommodating-students-disabilities-roles-and-responsibilities-fact-sheet

Pfeifer, M. A., Reiter, E. M., Cordero, J. J., \& Stanton, J. D. (2021). Inside and out: Factors that support and hinder the self-advocacy of undergraduates with ADHD and/or specific learning disabilities in STEM. CBE Life Sciences Education, 20(2), 1-20. https://doi.org/10.1187/cbe.20-06-0107

Pollock, W. (2009). The impact of on-line training on college faculty attitudes and knowledge of students with disabilities. Old Dominion University, ProQuest Dissertations Publishing.

Public Health Ontario. (2020). Coronavirus Disease 2019 (COVID-19). Retrieved from https://www.publichealthontario.ca/en/diseases-and-conditions/infectious-diseases/respiratory-diseases/novel-co ronavirus

Quinlan, M. M., Bates, B. R., \& Angell, M. E. (2012). 'What can I do to help?': Postsecondary students with learning disabilities' perceptions of instructors' classroom accommodations. Journal of Research in Special Educational Needs, 12(4), 224-233. https://doi.org/10.1111/j.1471-3802.2011.01225.x

Rashid, S., \& Yadav, S. S. (2020). Impact of Covid-19 pandemic on higher education and research. Indian Journal of Human Development, 14(2), 340-343. https://doi.org/10.1177/0973703020946700

Roberts, J. B., Crittenden, L. A., \& Crittenden, J. C. (2011). Students with disabilities and online learning: A cross-institutional study of perceived satisfaction with accessibility compliance and services. The Internet and Higher Education, 14(4), 242-250. https://doi.org/10.1016/j.iheduc.2011.05.004

Sachs, D., \& Schreuer, N. (2011). Inclusion of students with disabilities in higher education: Performance and participation in student's experiences. Disability Studies Quarterly, 31(2). https://doi.org/10.18061/dsq.v31i2.1593

Statistics Canada. (2007). Participation and activity limitation survey 2006: Analytical report. Statistics Canada Ministry of Industry, Ottawa, ON. 
Stewart, J. (2012). The educational outcomes of online learners: The predictive utility of disability status and self-efficacy. ProQuest Dissertations Publishing.

Thomas, C. (1999). Female forms: Experiencing and understanding disability. Buckingham; Philadelphia, Pa.: Open University Press.

Umucu, E., \& Lee, B. (2020). Examining the impact of COVID-19 on stress and coping strategies in individuals with disabilities and chronic conditions. Rehabilitation Psychology, 65(3), 193. https://doi.org/10.1037/rep0000328

VERBI Software. (2019). MAXQDA 2020. Berlin, Germany: VERBI Software. Retrieved from maxqda.com

Verdinelli, S., \& Kutner, D. (2016). Persistence factors among online graduate students with disabilities. Journal of Diversity in Higher Education, 9(4), 353-368. https://doi.org/10.1037/a0039791

Wendell, S. (2006). The Rejected Body: Feminist Philosophical Reflections on Disability. New York: Routledge. https://doi.org/10.4324/9780203724149

Westine, C., Oyarzun, B., Ahlgrim-Delzell, L., Casto, A., Okraski, C., Park, G., ... Steele, L. (2019). Familiarity, current use, and interest in universal design for learning among online university instructors. International Review of Research in Open and Distributed Learning, 20(5). https://doi.org/10.19173/irrodl.v20i5.4258

Wolpinsky, R. (2014). College students with learning disabilities and their lived experiences as online learners. ProQuest Dissertations Publishing.

Wuensch, K. L., Aziz, S., Ozan, E., Kishore, M., \& Tabrizi, M. H. N. (2008). Pedagogical characteristics of online and face-to-face classes. International Journal on E-Learning, 7(3), 523-532. http://www.learntechlib.org/p/24201/

Zhang, H., Nurius, P., Sefidgar, Y., Morris, M., Balasubramanian, S., Brown, J., ... Mankoff, J. (2021). How does COVID-19 impact students with disabilities/health concerns? ArXiv:2005.05438 [Cs]. Retrieved from http://arxiv.org/abs/2005.05438

\section{Copyrights}

Copyright for this article is retained by the author(s), with first publication rights granted to the journal.

This is an open-access article distributed under the terms and conditions of the Creative Commons Attribution license (http://creativecommons.org/licenses/by/4.0/). 